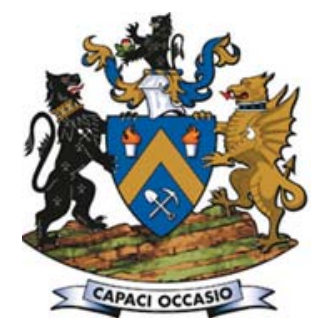

\title{
New approach to evaluate the TOWS matrix and its application in a mining company
}

\author{
by I. Černý*, M. Vaněk*, and J. Hubáček*
}

\section{Synopsis}

SWOT analyses and the closely related TOWS matrix are frequent starting points for an organization to develop its strategy. The paper deals with the evaluation of the TOWS matrix and presents three novel approaches to evaluate the different factors of the TOWS matrix, namely (1) approach to evaluate the factors with identical weights; (2) approach to evaluate factors with their weights determined within the different quadrants of the TOWS matrix; and (3) approach to evaluate factors with weights determined within the whole Tows matrix. The third approach has two variants. The proposed approaches to evaluate the TowS matrix were tested on a SWOT analysis of a significant mining company in the Czech Republic. The results imply that the strategy W-T (weaknesses-threats) is recommended in three cases, while the strategy $\mathrm{S}-\mathrm{T}$ (strengths-threats) is recommended once. The paper may be valuable for managers responsible for strategic planning.

Keywords

strategy, SWOT analysis, TOWS matrix, evaluation methods, mining company. times at the turn of the millennium could be expected to be turbulent (Drucker, 1969).

In addition, looking at a mining company in the context of the Eurozone debt crisis, the specific conditions may be aggravated by disturbances in the real economy. Vilamová (2012) claims that the avoidance of risk in the financial sector reduces the availability of credit, thus slowing economic growth and increasing unemployment. The key to investment and private consumption may be seen in restoring confidence in the financial market (Vilamová et al., 2012).

To be able to succeed in such demanding and complex conditions, management need to adopt responsible attitudes based on decisionmaking processes grounded in reliable information. In case of strategic management, the relevant information may be gained through a set of strategic analyses, such as Porter's model, BSG model, PESTEL, or SWOT analysis.

Special attention is paid here to SWOT analysis. We believe SWOT analysis has a somewhat privileged position among strategic analyses worldwide. SWOT is the acronym for strengths, weaknesses, opportunities, and threats. Earlier, the original acronym 'SOFT' stood for satisfactory (good in the present), opportunity (good in the future), fault (bad in the present), and threat (bad in the future) (Humphrey, 2005).

Later, a modification by Weihrich (1982) led to TOWS (SWOT backwards) in the format of a matrix, matching the internal factors (strengths and weaknesses) of an organization with its external factors (opportunities and threats) to systematically generate strategies to be undertaken (Hannah, 2011).

* Faculty of Mining and Geology, V̌̌B - Technical University of Ostrava, Czech Replublic.

(c) The Southern African Institute of Mining and Metallurgy, 2018. ISSN 2225-6253. Paper received Jun. 2015; revised paper received Apr. 2018. 


\section{New approach to evaluate the TOWS matrix and its application in a mining company}

Although the SWOT analysis does not consist of the mere breakdown of the different strengths and weaknesses, opportunities and threats, the breakdown of the interest area items represents the only output of the analysis. An evaluation of the analysis and the determination of the assessed entity's position in the TOWS matrix are often absent. Therefore, the analysis results may not accurately define a suitable strategy arising from the given or predicted internal or external environments.

Expert literature, for example Robbins (2007), Koontz (1990), Certo (2003), shows that authors usually pay attention to the description of SWOT analysis, but ignore its evaluation. An exception may be seen in the publication 'Marketing Management' by Kotler and Keller (2012), where to evaluate the opportunities he uses the attractiveness and probability of success, threats are evaluated by means of impact and probability of occurrence, and strengths and weaknesses are assessed by means of performance and importance of relevant areas. However, Kotler's approach does not result in a precise or unambiguous position in the TOWS matrix.

For this reason, we decided to search for such an approach that could help strategic managers to forsee which strategies to formulate for the companies they manage, and subsequently implement these in practice. As we do not want to limit ourselves to the theoretical level, we apply the proposed method to a particular company - OKD, a.s. (OKD, joint-stock company), one of the biggest mining companies in the Czech Republic.
2014 was a year of crisis for OKD as they faced bankruptcy. The management decided to redress the prevailing structural situation of the company. A SWOT analysis and its evaluation may be interesting not only for the management, but also for the wider expert public. The aim of this paper is to present the authors' approach to SWOT analysis evaluation and one practical application, on OKD, a.s.

\section{Methods and materials}

Being a well-known method for strategic analysis, the SWOT analysis or TOWS matrix is often described in expert literature on management. For details, see for example Robbins (2007), Koontz (1990), and Certo (2003).

The paper pays attention to the evaluation of the SWOT analysis and TOWS matrix. A SWOT analysis in organizations is usually prepared as a list of factors in the different areas of interest. When evaluating the factors, companies may encounter problems in determining the unambiguous weights of the different factors, and thus they assess them as equally substantial. Or, the factor weights are decided using decision-making processes in groups (e.g. brainstorming) based on paired comparison of the factors (Saaty's method, Fuller's triangle) within the four quadrants of the TOWS matrix. Nevertheless, the determination of factor weights (preference) on the grounds of paired comparison of factors belonging to various TOWS matrix quadrants is not a common practice.

\section{Table I}

The steps of development and evaluation of the OWS matrix

\begin{tabular}{|c|c|c|}
\hline Step & Activity & Results \\
\hline Zero step & $\begin{array}{l}\text { Preparation of SWOT analysis. } \\
\text { Ask experts from academia and the business sector for their } \\
\text { opinions and advice to ensure a pluralistic approach. }\end{array}$ & $\begin{array}{l}\text { Following Janíček (2013), we established an expert team of five } \\
\text { members. These were people both from academia and } \\
\text { management. }\end{array}$ \\
\hline First step & $\begin{array}{l}\text { Classification of the different factors in the TOWS matrix by } \\
\text { brainstorming. }\end{array}$ & Table III \\
\hline Second step & $\begin{array}{l}\text { Determination of the approaches to evaluate the different } \\
\text { weights of each factor that tally with the real preconditions } \\
\text { for certain companies or sectors. } \\
\text { the TOWS matrix }\end{array}$ & $\begin{array}{l}\text { Approach } 1 \text { - criteria to assess the factor weights cannot be easily } \\
\text { determined } \\
\text { Approach } 2 \text { - in other companies criteria to evaluate factor } \\
\text { weights can be determined only within the individual quadrants of } \\
\text { Approach } 3 \text { - in the remaining companies, based on the selected } \\
\text { criteria it is possible to determine the factor weight, namely on the } \\
\text { grounds of an overall comparison of all factors from all quadrants } \\
\text { of the TOWS matrix. }\end{array}$ \\
\hline Third step & Proposal of criteria to determine the factor weights. & $\begin{array}{l}\text { For the second approach, the criterion selected was the impact } \\
\text { (positive or negative) of a given factor on an entity/sector. } \\
\text { For the third approach, we divided all the factors of the TOWS } \\
\text { matrix into categories, among which unambiguous preferential } \\
\text { relationships were established. For example, if category A is } \\
\text { preferred to category B, all the factors falling into category A also } \\
\text { have a higher weight than factors belonging to category B. The } \\
\text { factor weights within a given category may be determined based } \\
\text { on the impact criterion. }\end{array}$ \\
\hline Fourth step & $\begin{array}{l}\text { Selection of the method to evaluate the factor weights. } \\
\text { The most applied methods include order method, scoring } \\
\text { method, Fuller's triangle, and Saaty's method (Perzina, 2014). }\end{array}$ & $\begin{array}{l}\text { Considering the high number of factors, and difficulty in } \\
\text { identifying an explicit order of the factors or their clear scoring, we } \\
\text { chose the method of paired comparison, namely Fuller's triangle. } \\
\text { The Fuller's triangle method enables an easy and unambiguous } \\
\text { comparison of factors. }\end{array}$ \\
\hline Fifth step & Preparation of the methods to evaluate the TOWS matrix. & $\begin{array}{l}\text { For each of the approach we determined a method to calculate } \\
\text { the TOWS matrix. The third approach discussed was prepared } \\
\text { in two options and was subjected to modelling. }\end{array}$ \\
\hline
\end{tabular}




\section{New approach to evaluate the TOWS matrix and its application in a mining company}

The major aim of the authors here is to offer the expert public, and especially the business sector, a complex approach to the evaluation of the TOWS matrix. To meet this need, we used the procedures and methods described in Table I.

\section{The mining company under consideration}

We decided to verify the proposed approaches to TowS matrix evaluation using a SWOT analysis of the mining company OKD, a.s. OKD is the sole producer of hard coal (bituminous coal) in the Czech Republic, and operates in the southern part of the Upper Silesian Coal Basin in the OstravaKarviná coal district. According to the official company website, OKD prospects for, extracts, processes, and sells hard coal with low contents of sulphur and other impurities. The coal is used as fuel, for coke production, in the chemical industry, and many other sectors (Raška, 2014).

Currently, OKD operate three active mines and one mine is on care and maintenance. The mining operations are listed below:
> Mining operation 1 (mining sites SA, Lazy, and Darkov)

> Mining operation 2 (mining sites North and South)

> Mining operation 3 (mining sites Staříc and Chlebovice)

The Frenštát Mine is on care and maintenance.

Between 2009 and 2014 the annual production was about 8-11 Mt of coal suitable for coking or as energy coal.

As of 31 December 2013, OKD had 11763 employees and another 3200 people worked through contractor companies. The economically mineable reserves of the company as of 31 December 2013 exceeded $64 \mathrm{Mt}$.

Selected economic performance parameters for 20092013, are presented in Table II.

Table III gives the SWOT analysis of the company.

\section{Results}

We prepared three approaches to evaluate the different factors of the TOWS matrix:

Table /I

Selected economic performance parameters for OKD a.s., 2009 - 2013

\begin{tabular}{|c|c|c|c|c|c|}
\hline Year & 2009 & 2010 & 2011 & 2012 & 2013 \\
\hline Coal extracted, kt & 10621 & 11193 & 10967 & 10796 & 8610 \\
\hline Pre-tax profit, CZK million & 1991 & 7104 & 7533 & 1549 & -23857 \\
\hline Operation economic performance result, CZK million & 2675 & 7890 & 8326 & 2179 & -21878 \\
\hline Net operation cash flow ${ }^{\star}, \mathrm{CZK}$ million & 5800 & 10916 & 11870 & 6494 & -1170 \\
\hline Company total assets, CZK million & 50497 & 47266 & 48434 & 43203 & 22110 \\
\hline Total company internal staff & 14331 & 13693 & 13305 & 13068 & 12369 \\
\hline Total staff of supplier firms & Unavailable & 3679 & 4435 & 4571 & 3704 \\
\hline
\end{tabular}

*Before taxation, working capital changes, and extraordinary items; figures in red indicate negative values Source: OKD, 2009, 2010, 2011, 2012, 2013

SWOT analysis of OKD a.s.

\begin{tabular}{|c|c|}
\hline Strengths & Weaknesses \\
\hline S1 - Know-how $(27 ; 5 ; 18 ; 13)$ & W1 - Limited reserves $(27 ; 4 ; 18 ; 6)$ \\
\hline $\begin{array}{l}\text { S2 - Thick seams }(27 ; 6 ; 18 ; 14) \\
(27 ; 7 ; 22 ; 21)\end{array}$ & W2 - Anomalous phenomena (methane, rock bumps, aquifers, outbursts) \\
\hline S3 - Possible extraction of methane $(27 ; 5 ; 18 ; 13)$ & W3 - Deeper operations (higher temperatures $(27 ; 6 ; 18 ; 6)$ \\
\hline $\begin{array}{l}\text { S4 - Modern technology }(27 ; 2 ; 18 ; 10) \\
(27 ; 3 ; 18 ; 3)\end{array}$ & W4 - Adaptation of modern technology to specific mine conditions \\
\hline S5 - Existence of 'Continuous Improvement' project $(27 ; 0 ; 18 ; 0)$ & W5 - Uncertain sales and cost conditions $(27 ; 1 ; 27 ; 26)$ \\
\hline S6 - Emphasis on safety $(27 ; 2 ; 18 ; 10)$ & W6 - Intensity of operations of modern technology $(27 ; 3 ; 18 ; 3)$ \\
\hline \multirow[t]{2}{*}{ S7 - Coal quality $(27 ; 5 ; 18 ; 13)$} & W7 - Higher demands for staff qualification $(27 ; 0 ; 18 ; 1)$ \\
\hline & $\begin{array}{l}\text { W8 - Mining progressively deeper and non-uniform thickness } \\
\text { (Ostrava Member) }(27 ; 5 ; 18 ; 6)\end{array}$ \\
\hline Opportunities & Threats \\
\hline O1 - Use of new mining methods $(27 ; 1 ; 18 ; 10)$ & T1 - Long-term fall in coal prices on the world markets $(27 ; 6 ; 27 ; 27)$ \\
\hline O2 - Potential extraction in Mine Frenštát pod Radhoštěm $(27 ; 5 ; 18 ; 18)$ & T2 - Stagnation or decrease in coal sales $(27 ; 6 ; 27 ; 26)$ \\
\hline O3 - Potential extraction in the border area near Poland $(27 ; 5 ; 18 ; 18)$ & T3 - Deterioration of geological conditions $(27 ; 3 ; 22 ; 21)$ \\
\hline O4 - Potential employment of agency workers from Poland $(27 ; 1 ; 18 ; 10)$ & T4 - Deterioration of gas and hydrogeological conditions $(27 ; 3 ; 22 ; 21)$ \\
\hline $\begin{array}{l}\text { O5 - An increase in coal utilization (coke) in other industrial branches } \\
\text { (e.g. pharmaceuticals, chemistry) }(27 ; 3 ; 18 ; 16)\end{array}$ & T5 - Higher input costs (material, energy) $27 ; 1 ; 27 ; 26$ ) \\
\hline O6 - Secondary use of methane $(27 ; 3 ; 18 ; 16)$ & T6 - Pressure to increase wages $(27 ; 1 ; 27 ; 23)$ \\
\hline T7 - Requests by eco-activities (activists) in the new localities $(27 ; 6 ; 22 ; 22)$ & \\
\hline
\end{tabular}




\section{New approach to evaluate the TOWS matrix and its application in a mining company}

Approach to evaluate the factors with identical weights

> Approach to evaluate factors with their weights determined within the different quadrants of the Tows matrix

- Approach to evaluate factors with weights determined within the whole TOWS matrix.

The first approach builds upon the fact that it is not possible to compare factor preferences either within each quadrant, i.e. $\mathrm{S}, \mathrm{W}, \mathrm{O}, \mathrm{T}$, or among the different quadrants. All the factors in each quadrant $(\mathrm{S}, \mathrm{W}, \mathrm{O}, \mathrm{T})$ have identical significance (weight, preference).

$\mathrm{V}=\mathrm{N}-1$

$\mathrm{N}=\mathrm{PS}+\mathrm{PW}+\mathrm{PO}+\mathrm{PT}-1$

where: $\mathrm{v}$ is the weight of each factor; $\mathrm{N}$ the total number of factors from all quadrants $(\mathrm{S}, \mathrm{W}, \mathrm{O}, \mathrm{T})$ of the TOWS matrix; PS the number of factors in the S quadrant; PW the number of factors in the W quadrant; PO the number of factors in the $\mathrm{O}$ quadrant; and PT the number of factors in the T quadrant.

The second approach proceeds from the fact that it is possible to determine factor weights within the different quadrants $(\mathrm{S}, \mathrm{W}, \mathrm{O}, \mathrm{T})$ of the TOWS matrix by comparing their preferences, but not by comparing the factor preferences from different quadrants (Vaněk et al., 2014).

Expert literature offers several options to evaluate the first phase of the SWOT analysis (e.g. Saaty's method, Fuller's triangle, evaluation according to Kotler). We decided to evaluate the SWOT analysis of the studied company using the weighting evaluation method, where the weights were set using the method of paired comparison and the Fuller's triangle.

The evaluation process using weights is grounded in the following steps:

> Fuller's triangles are constructed for the different evaluated quadrants $(\mathrm{S}, \mathrm{W}, \mathrm{O}, \mathrm{T})$ of the TOWS matrix based on the number of identified factors and facts.

> A paired comparison of factors and facts is carried out for the different quadrants of the TOWS matrix. The preferred factors and facts are marked (e.g. in colour, in bold). If factors in a pair have identical preferences, we mark both.

> According to their preferences, the absolute weights of the factors and facts are determined as follows:

$$
v_{i}=\sum_{j \neq i}^{n} P_{i j}
$$

where:

$v_{i}$ is the weight of the $i$ factor/fact in the given quadrant under evaluation $(\mathrm{S}, \mathrm{W}, \mathrm{O}, \mathrm{T})$

$P_{i j}=1$ - preference of $i \geq$ preference of $j$; it is a bivalent variable $(0,1)$ that expresses the factor preference in the paired comparison of the factors $i$ and $j$

$i$ is the index of factor/fact in the given quadrant ( $\mathrm{S}, \mathrm{W}, \mathrm{O}$, T) $i=\{1, \ldots, \mathrm{n}\}$

$j$ is the index of factor/fact in the given quadrant $(\mathrm{S}, \mathrm{W}, \mathrm{O}$, T) $j=\{1, \ldots, \mathrm{n}\}$

$s n$ is the number of factors/facts in the given quadrant under evaluation $(\mathrm{S}, \mathrm{W}, \mathrm{O}, \mathrm{T})$.

> Next, we determine a scoring number for the evaluated quadrant of the TOWS matrix as the sum of the weights of the different factors and facts:

$$
H_{X}=\sum_{i=1}^{n} v_{i}
$$

where:

$H_{X}$ is the scoring number for the evaluated quadrant $X$

$X \quad$ is the quadrant under evaluation $(\mathrm{S}, \mathrm{W}, \mathrm{O}, \mathrm{T})$

$v_{i} \quad$ is the weight of the $i$ factor/fact in the evaluated quadrant $X$

$i$ is the index of factor/fact in the evaluated quadrant $X$

$n$ is the number of factors/facts in the evaluated quadrant $X$.

> Finally, we determine a scoring number $(\mathrm{H})$ for the individual strategic types (i.e. S-O, S-T, W-O, W-T) as the product of the scoring numbers of the different quadrants of the TOWS matrix, as expressed by the Equations [5]-[8]:

$$
\begin{aligned}
& H_{S O}=H_{S} \cdot H_{O} \\
& H_{S T}=H_{S} \cdot H_{T} \\
& H_{W O}=H_{W} \cdot H_{O} \\
& H_{W T}=H_{W} \cdot H_{T}
\end{aligned}
$$

It is clear that the maximum scoring number for the different strategic types defines the inquired quadrant of the matrix and thus the relevant strategic type (ST):

$$
S T=\max \left(H_{S O}, H_{S T}, H_{W O}, H_{W T}\right)
$$

The third approach builds on the fact that it is possible to compare the factor preferences within the different quadrants of the TOWS matrix as well as among the quadrants at the same time (e.g. the significance of a certain factor from the area ' $\mathrm{S}$ ' is much higher than that from the area ' $\mathrm{T}$ '). It is advisable to subject the approach to modelling using two variants.

The first variant consists of the classification of all factors from the quadrants S, W, O, T of the TOWS matrix into categories, among which preferential relations are clearly given. This means that the categories are not indifferent to preferences. However, it also holds true that all the factors within each category are indifferent to preferences, i.e. they have identical significance (weight). In the sector under condideration, i.e. the mining industry, it is possible to arrange the different factors of the $\mathrm{S}, \mathrm{W}, \mathrm{O}$, T quadrants into clearly set categories of preference as follows.

> Political factors have the top priority. These are, for instance, support for sustainable mining or of other systems of subsidies to overcome unfavourable barriers to business development, cost, and natural and environmental barriers. However, political factors are not taken into account in this paper as the Czech government has not clearly declared long-term support for the mining industry. If the government showed a green light for the mining industry as a strategic sector, this factor/these factors could be attributed to the quadrant of Opportunities.

> Business and cost factors represent the second top priority. There is accessibility and availability of raw materials, competition in the studied area, purchasing power of citizens and organizations, etc. Among the business and cost factors, there are clearly T1, T2, T5, T6, and W5 (Table III). 


\section{New approach to evaluate the TOWS matrix and its application in a mining company}

- Natural and environmental factors rank third among the preference group factors. We can classify herein safe mine operations with excess exploitation in the studied area, and urban and landscape attractiveness of the area in question. Among the natural and environmental factors, there are $\mathrm{T} 3, \mathrm{~T} 4, \mathrm{~T} 7$, and $\mathrm{W} 2$ (Table III).

$>$ Other factors (unclassified) include all factors that cannot be allocated unambiguously (Table III).

According to the abovementioned assumptions, we may determine the following weights:

$$
\begin{aligned}
& v_{P}>v_{B}>v_{E}>v_{O} \\
& v_{P}=N_{1}
\end{aligned}
$$

where

$v_{P}$ is the weight of the political factors.

$$
v_{B}=\mathrm{N}-1-\mathrm{K}_{p}
$$

where $v_{B}$ is the weight of the business and cost factors; $K_{P}-$ is the number of political factors.

$$
\mathrm{v}_{E}=N-1-K_{P}-K_{B}
$$

where: $v_{E}$ is the weight of the natural and environmental factors.

$$
K_{B} \text { - is the number of business and costs factors. }
$$$$
\mathrm{v}_{O}=N-1-K_{P}-K_{B}-K_{E}
$$

where $v_{O}$ is the weight of other factors.

$K_{E}$ is the number of natural and environmental factors.

The scoring number for the evaluated quadrant of the TOWS matrix is determined as follows:

$$
H_{X}=P_{X P} v_{P}+P_{X B} v_{B}+P_{X E} v_{E}+P_{X O} v_{O}
$$

where

$P_{X P}$ is the number of factors in the quadrant $X(\mathrm{~S}, \mathrm{~W}, \mathrm{O}, \mathrm{T})$ belonging to the category of political factors

$P_{X B}$ is the number of factors in the quadrant $X(\mathrm{~S}, \mathrm{~W}, \mathrm{O}, \mathrm{T})$ belonging to the category of business and cost factors

$P_{X E}$ is the number of factors in the quadrant $X(\mathrm{~S}, \mathrm{~W}, \mathrm{O}, \mathrm{T})$ belonging to the category of natural and environmental factors

$P_{X O}$ is the number of factors in the quadrant $X(\mathrm{~S}, \mathrm{~W}, \mathrm{O}, \mathrm{T})$ belonging to the category of other (unclassified) factors.

The scoring numbers for the different strategic types (S-O, S-T, W-O, W-T) are calculated according to Equations [5] to [8]. A strategic type is chosen according to Equation [9].

The second variant, similarly to the first variant of the third approach, lies in the classification of all factors from the areas S, W, O, T into categories, among which there are clear preferential relations (Equation [10]). In contrast to the first variant, it holds true for the second variant that all the factors which make part of the given category are mutually different, i.e. they differ in their significance. In principle, it is a combination of the third and second approaches, which increases the practical applicability of the SWOT analysis The procedures to implement the variant may be set as follows.

Partial factors within the individual categories have different preferences. Therefore, it is vital to determine the weights of the partial factors within the different categories as follows:

$$
\begin{aligned}
\mathrm{v}_{P i} & =N-1-\left(K_{P}-1-\sum_{i \neq j} P_{i j}\right) \\
\mathrm{V}_{B i} & =N-1-K_{P}-\left(K_{B}-1-\sum_{i \neq j} P_{i j}\right) \\
\mathrm{v}_{E i} & =N-1-K_{P}-K_{B}-\left(K_{E}-1-\sum_{i \neq j} P_{i j}\right) \\
\mathrm{v}_{O i} & =N-1-K_{P}-K_{B}-K_{E}-\left(K_{O}-1-\sum_{i \neq j} P_{i j}\right)
\end{aligned}
$$

where $v_{P i}$ is the weight of the $i$ political factor; $v_{B i}$ is the weight of the $i$ business and cost factor; $v_{E i}$ is the weight of the $i$ natural and environmental factor; $v_{O} i$ is the weight of the $i$ other (unclassified) factor; and $K_{O}-$ is the number of other (unclassified) factors.

The scoring number for the evaluated quadrant X $(\mathrm{S}, \mathrm{W}$, $0, T$ ) of the TOWS matrix is determined according to Equation [20]:

$$
H_{X}=\sum_{i=1}^{P_{x p}} v_{P i}+\sum_{i=1}^{P_{x b}} v_{B i}+\sum_{i=1}^{P_{x e}} v_{E i}+\sum_{i=1}^{P_{x o}} v_{O i}
$$

The scoring numbers for the various strategic types (S-O, S-T, W-O, W-T) are calculated according to Equations [5] to [8]. A strategic type is chosen according to Equation [9].

For the second variant, it is necessary to set up factor preferences within the categories based on transitivity. Transitivity arises from a specific SWOT analysis. Political factors are not examined herein, as explained above. For the business and cost factors, the hierarchy of preferences may be determined as follows:

$$
T_{1}>T_{2}=W_{5}=T_{5}>T_{6}
$$

The relationship stated above is grounded in the fact that the long-term fall in coal prices on the world market $\left(T_{1}\right)$ is unsustainable for the mining industry and cannot be influenced without political intervention. Therefore, it has the top priority. Factors $\left(T_{2}, W_{5}, T_{5}\right)$ that represent stagnation, uncertain sales, or an increase in input costs can be influenced, for example, by improving the industrial logistics and savings (sales may slacken even at good price levels). However, such factors are more significant than factor $T_{6}$ (pressure to increase wages), which is much more easily influenced (e.g. by collective bargaining), especially in the regions of so-called 'old industry', where there is a general shortage of new jobs.

Natural and environmental factors may be organized into a hierarchy as below:

$$
T_{7}>T_{3}=T_{4}=W_{2}
$$

The increasing requests by eco-activitists (T7) and changes in the general public's attitudes to the natural environment may have a political impact on decision-making about the strategic priorities and investments. This factor is very difficult to influence, and thus may be considered as the most important in the given category. Other environmental and natural factors $\left(T_{3}, T_{4}, W_{2}\right)$ are given by the natural conditions only, and it is thus difficult to identify which factor is the most significant.

The other (unclassified factors) make up the biggest set of factors (about 19). Brainstorming must be used to assess these. The authors of this paper participated in the brainstorming session. In business, it is routinely possible to evaluate the different factors within the quadrants $\mathrm{S}, \mathrm{W}, \mathrm{O}$, and T. However, the problem lies in the comparison of factors 


\section{New approach to evaluate the TOWS matrix and its application in a mining company}

from different quadrants. Such a comparison is rarely done in business. As a result, the following two-stage process of factor comparison can be recommended.

In the first stage, we compare the factors within the individual quadrants $\mathrm{S}, \mathrm{W}, \mathrm{O}, \mathrm{T}$ based on transitivity.

Strengths

$S_{2}>S_{1}=S_{3}=S_{7}>S_{4}=S_{6}>S_{5}$

Weaknesses

$W_{1}=W_{3}=W_{8}>W_{4}=W_{6}>W_{7}$

Opportunities

$\mathrm{O}_{2}=\mathrm{O}_{3}>\mathrm{O}_{5}=\mathrm{O}_{6}>\mathrm{O}_{1}=\mathrm{O}_{4}$

\section{Threats}

No threats are classified in the 'other' factors.

In the second stage, it is vital to compare the factors from the different quadrants $\mathrm{S}, \mathrm{W}, \mathrm{O}$, and $\mathrm{T}$ making use of the transitivity characteristics. The algorithm arises from the comparison of the most preferred factors from the quadrants, and we continue with comparing at the lower level of preference according to transitivity.

$$
\begin{aligned}
& \mathrm{O}_{2}>S_{2}>W_{1} ; O_{5}>S_{2}>O_{1} ; S_{1}>O_{1} ; S_{4}=O_{4} ; S_{1}> \\
& W_{1} ; S_{4}>W_{1} ; W_{1}>S_{5} ; W_{5}>S_{5} ; W_{7}>S_{5} ; O_{1}>W_{1}
\end{aligned}
$$

Based on the above stated relationships, from the twostage process of factor comparison using the transitivity rules it is possible to determine an overall comparison of all factors from the different quadrants $\mathrm{S}, \mathrm{W}, \mathrm{O}$, and $\mathrm{T}$ within the category of other (unclassified) factors as follows:

$$
\begin{aligned}
& \mathrm{O}_{2}=\mathrm{O}_{3}>\mathrm{O}_{5}=\mathrm{O}_{6}>S_{2}>S_{1}=S_{3}=S_{7}>S_{4}=S_{6}= \\
& \mathrm{O}_{1}=O_{4}>W_{1}=W_{3}=W_{8}>W_{4}=W_{6}>W_{7}>S_{6}
\end{aligned}
$$

\section{Discussion}

The prepared SWOT analysis has become the point of departure to apply the proposed methods in the TOWS matrix evaluation.

We determined the preferences of the factors/facts in the paired comparison. Table III shows the weights of the items (in the round brackets, weights ranking to the different approaches are separated by a semicolon).

Table IV gives the scoring numbers for the TOWS matrix quadrants and strategic types calculated according to Equations [4] to [27].

Summing up the weights of the factors in the different quadrants of the TOWS matrix, we produced the scoring numbers for the quadrant, which were the points of departure to calculate the scoring numbers for the strategic types (see Table IV).

The results imply that the company managers face a decision whether to close the company or whether the company strengths should be used to suppress the threats. In the latter case, the state authorities could play a positive role and the impact of this could even boost the company strengths.

In three cases the company should enforce a total phaseout (Table III); only on the basis of the third approach, second variant, should the strengths of the company be exploited to suppress the threats. This difference is particularly due to the opportunity of comparing the different factors within the categories. It is clear that the majority of factors from quadrants $\mathrm{S}$ and $\mathrm{W}$ of the ToWS matrix are classified into the 'other' factors. Five out of six factors from quadrant $\mathrm{S}$ have a higher preference than the six factors from the quadrant $\mathrm{W}$.

Nevertheless, it is apparent from the comparison of the scoring numbers for the strategic types in the third approach, second variant, that the difference between the optimal strategic type and the second-best variant is minimal.

Comparing our results with the real conditions of the company OKD, the results reflect the actual state of the mining company. Unfavourable economic results of OKD and the difficult financial situation of the owner, New World Resources (NWR), meant that the managers of both companies had to become crisis managers.

Since 2013 bankruptcy has been a real threat to OKD, as indicated in Table II. In August 2014 bondholders authorized NWR to undergo capital restructuring. The restructuring was also approved by courts in the UK and the USA. NWR and thus OKD were given a chance to stabilize their current situations and search for future solutions .

\section{Conclusion}

The managements of organizations are facing tough and complex decisions in the current turbulent economic conditions as strategies to ensure prosperity and success are difficult to formulate. The quality of a strategy undoubtedly mirrors the quality of strategic analyses carried out. The SWOT analysis is the key one as it considers both the internal and external conditions of an organization. The TOWS matrix, grounded in the SWOT analysis, thus may become a tool to formulate a suitable strategy.

Having studied the issues, we learn that the evaluation of the TOWS matrix is basically neglected. For that reason, we have prepared three approaches to evaluate the factors in the TOWS matrix (an approach to evaluate the factors with identical weights; an approach to evaluate factors with their weights determined within the different quadrants of the TOWS matrix; and an approach to evaluate factors with weights determined within the whole TOWS matrix).

The proposed approaches have been tested on the TOWS matrix of the mining company OKD a.s. We believe that the verification of the approaches was successful and confirmed our expectations. The functionality of the proposed approaches is also documented by the comparison of the evaluation conclusions with the real conditions in OKD a.s.

At this moment, it is too early to say whether those approaches will become common practice for users of SWOT analysis, as they need to be subjected to expert discussion. We are persuaded that the new approaches have a chance for success, namely with regard to the limited possibilities the TOWS matrix may currently offer to its users.
*20KD. About us http://www.okd.cz/en/about-us [accessed 15 January 2015]. 


\section{New approach to evaluate the TOWS matrix and its application in a mining company}

\begin{tabular}{|c|c|c|}
\hline \multicolumn{3}{|c|}{$\begin{array}{l}\text { Table IV } \\
\text { Scoring numbers for the TOWS matrix identified based on all the approaches }\end{array}$} \\
\hline \multicolumn{3}{|c|}{ The first approach to the TOWS matrix evaluation } \\
\hline & HS = 189 & $H W=216$ \\
\hline $\mathrm{HO}=162$ & $\mathrm{HSO}=30618$ & $\mathrm{HWO}=34922$ \\
\hline $\mathrm{HT}=189$ & $\mathrm{HST}=35721$ & $\mathrm{HWT}=40824$ \\
\hline \multicolumn{3}{|c|}{ The second approach to the TOWS matrix evaluation } \\
\hline & $\mathrm{HS}=25$ & $H W=29$ \\
\hline $\mathrm{HO}=18$ & $\mathrm{HSO}=450$ & $\mathrm{HWO}=522$ \\
\hline $\mathrm{HT}=26$ & $\mathrm{HST}=650$ & $\mathrm{HWT}=754$ \\
\hline \multicolumn{3}{|c|}{ The third approach to the TOWS matrix evaluation - first variant } \\
\hline & $H S=126$ & $H W=157$ \\
\hline $\mathrm{HO}=108$ & $\mathrm{HSO}=13608$ & $\mathrm{HWO}=16956$ \\
\hline $\mathrm{HT}=174$ & $\mathrm{HST}=21924$ & $H W T=27318$ \\
\hline \multicolumn{3}{|c|}{ The third approach to the TOWS matrix evaluation - second variant } \\
\hline & $\mathrm{HS}=73$ & $\mathrm{HW}=72$ \\
\hline $\mathrm{HO}=88$ & $\mathrm{HSO}=6424$ & $\mathrm{HWO}=6336$ \\
\hline $\mathrm{HT}=166$ & $\mathrm{HST}=12118$ & HWT $=11952$ \\
\hline
\end{tabular}

\section{Acknowledgement}

The authors would like to thank their advisers for valuable information.This research was financed under the support of specific university research project no. SP2015/11, granted by the Ministry of Education, Youth and Sport of the Czech Republic.

\section{References}

CERTO, S.C. 2003. Modern Management: Adding Digital Focus. 9th edn. Prentice Hall, Englewood Cliffs, NJ.

DRUCKER, P.F. 1969. The age of discontinuity: guidelines to our changing society. Heinemann, London.

Hannah, K., Ka Yin, Ch. Leung Chi, K., Sonbai, L., and Shu Chuen, T. 2011, A structured SWOT approach to develop strategies for the government of Macau, SAR. Journal of Strategy and Management, vol. 4, no 1. pp. 62-81. http://www.emeraldinsight.com/doi/pdfplus/ 10.1108/17554251111110122 [accessed 10 March 2015]

HumPHREY, A. 2005. SWOT analysis for management consulting. Stanford Research Institute Alumni Newsletter (SRI International), pp 7-8. http://www.sri.com/sites/default/files/brochures/dec-05.pdf [acessed 10 March 2015].

JANí̌̌EK, P. and Jǐs̆, M. 2013. Expertní inženýrství v systémovém pojetí (Expert engineering in system concept). Grada Publishing, Praha.

Koontz, H. and WeIHRIck, H. 1990. Essentials of Management. 5th edn. McGraw-Hill, New York.

OKD, A.S. 2009, 2010, 2011, 2012, 2013. Annual Reports. http://www.okd.cz/en/about-us/annual-reports [accessed 16 January 2015].
OKD. (Not dated). About us. http://www.okd.cz/en/about-us [accessed 16 January 2015].

Perzina, R. and Ramík, J. 2014. Microsoft Excel as a tool for solving multicriteria decision problems. Proceedings of the 18th International Conference on Knowledge-Based and Intelligent Information \& Engineering Systems - KES2014, Gdynia, Poland, 15-17 September 2014. Procedia Computer Science, vol. 35. pp. 1455-1463.

RAŠKA, J. 2014. NWR dostalo od majitel dluhopis souhlas k provedení restrukturalizace (komentá ). http://www.fio.cz/zpravodajstvi/zpravy-zburzy/151624-nwr-dostalo-od-majitelu-dluhopisu-souhlas-k-provedenirestrukturalizace-komentar [accessed 10 March 2015].

RobBins, S.P. and Coulter, M.K. 2007. Management. 9th edn. Pearson Prentice Hall, Englewood Cliffs, NJ.

SтоJANović, C. 2013. Evaluating investment projects in mining industry by combining discount method and real option valuation. Acta Montanistica Slovaca, vol. 19, no. 4. pp. 217-225.

VANĚK, M., ČERnÝ, I., HudeČEK, V., KRČMARSKÁ, L., and MAGNuSKovÁ, J. 2014. SWOT analysis - point of departure for strategic managers. Proceedings of the 14th International Multidisciplinary Scientific GeoConference (SGEM2014): GeoConference on Science and Technologies in Geology, Exploration and Mining, Albena, Bulgaria, 16-26 June 2014. Volume III STEF92 Technology Ltd. pp. 591-598.

VILAMovÁ, Š., JANovSKÁ, K., KozEL, R., VozŇÁKovÁ, I., and ŠvecovÁ, E. 2012. NeW trends in the management within the metallurgy firms. METAL 2012: Proceedings of the 21st International Conference on Metallurgy and Materials, Brno, Czech Republic, 23-25 May 2012. Tanger, Ostrava. pp. 1897-1903.

WEIHRICH, H. 1982. The TOWS matrix: a tool for situational analysis. Journal of Long Range Planning, vol. 15, no. 2. pp. 54-66.

http://www.usfca.edu/fac_staff/weihrichh/docs/tows.pdf [accessed 10 March 2015]. 